\title{
Nanoparticle-facilitated Intratumoral Delivery of Bcl-2/IGF-1R siRNAs and p53 Gene Synergistically Inhibits Tumor Growth in Immunocompetent Mice
}

\author{
Anil Philip Kunnath', Nur Izyani Kamaruzman² and Ezharul Hoque Chowdhury²* \\ ${ }^{1}$ Faculty of Medicine and Health Sciences, IMU, Malaysia \\ ${ }^{2}$ Advanced Engineering Platform and Jeffrey Cheah School of Medicine and Health Sciences, Monash University Malaysia
}

\begin{abstract}
Breast cancer, the leading cause of cancer-related deaths in women, is usually treated with surgery, radiation therapy, hormone-blocking/chemotherapy drugs, monoclonal antibodies or combinations of these approaches and agents depending on the cancer stage and the existence of specific receptors, with accompanying various adverse effects. Silencing of the genes responsible for cancer development and progression with small interfering RNA (siRNA) in combination with overexpression of the genes with tumor suppressing activities could be an attractive concept for precisely treating breast cancer with minimal side effects. However the short half-life in plasma due to nuclease-mediated degradation and renal clearance, and the inefficiency in penetrating the plasma membrane limit the applications of siRNA and DNA as therapeutic molecules. Recently, we have developed pH-sensitive carbonate apatite nano-carrier to efficiently deliver siRNA or DNA across the cell membrane facilitating them to escape endosomal acidic compartment and specifically cleave a cytoplasmic mRNA transcript or enable gene expression after nuclear translocation, respectively. Moreover, we demonstrated nanoparticle-accelerated delivery of the siRNAs targeting cyclin B1, PLC-gamma-2/ calmodulin1, HER2/ErbB2, ABCG2/ABCB1 and cROS1 mRNAs sensitizes cervical adenocarcinoma and breast cancer cells towards conventional anti-cancer drugs. Here, we report that co-delivery of the siRNAs targeting IGF-1R and $\mathrm{Bcl}-2$ gene transcripts and the pasmid DNA containing p53 gene with the help of carbonate apatite nanoparticles synergistically induces inhibition of growth/proliferation of breast cancer cell lines as well as regression of the breast tumor induced in Balb/c mice. Additionally, concerted delivery of nanoparticle-associated IGF-1R/Bcl-2 siRNAs and p53 gene apparently slows down the growth of the established tumor in presence of doxorubicin or paclitaxel compared with the individual free drugs. Thus, the combination of IGF-1R/Bcl-2 knockdown and restoring of normal p53 function could be a highly promising approach that should be further investigated through pre-clinical trials to establish the therapeutic role of this combination therapy for breast cancer.
\end{abstract}

Keywords: Carbonate apatite; siRNA; Gene expression; Transfection; Breast cancer; HER2/ErbB2; p53; Doxorubicin; Paclitaxel; Cisplatin; Chemosensitivity

Abbreviations: DMEM: Dulbecco's Modified Eagle's Medium; siRNA: small interfering RNA; IGF: Insulin-like growth factor; IGF1R: IGF-1 receptor; MAPK: Mitogen-activated Protein Kinase; PI3Ks: Phosphatidylinositol 3-kinases; ER: Estrogen Receptor; PR: Progesterone Receptor

\section{Introduction}

Breast cancer is the most common female cancer with more than 400,000 annual deaths world-wide. Among the three clinically categorized breast cancer patients, the first two groups having either estrogen receptor (ER) [1,2] or amplified HER2/ErbB2 gene [3], receive receptor-specific therapy while for the third group (Triple Negative) having neither of the three receptors, such as ER, progesterone receptor (PR) and HER2/ERBB2, cytotoxic chemotherapy remains the mainstay of treatment $[4,5]$. Since breast cancer is a heterogeneous disease characterized by different gene expression patterns depending on its sub-types, various approaches targeting growth factor signaling, angiogenic processes or apoptotic pathways are currently under investigation in order to improve the clinical outcomes [6-11].

Insulin-like growth factor (IGF) and its signaling pathway are implicated in development and progression of breast cancer [12]. Among the members of IGF family, IGF-1 and IGF-2 can bind to and activate IGF-1 receptor (IGF-1R) which is over-expressed in about $90 \%$ of breast cancer cases [13]. Although activation of the IGF-1R by IGF-1 is not an oncogenic event, survival of the cells transformed by proto-oncogene activation heavily relies on IGF-1 action [14-16]. IGF-1R has, however, been reported to play a role in invasion and metastasis of breast cancer cells [17-19]. Some rare mutations reported in IGF-1R were associated with mere growth retardation without an effect on cancer development or neoplasia [20-21]. Activation of the receptor results in either the activation of the Ras / Raf / MAP kinase pathway leading to cell proliferation or activation of Akt/PKB pathway regulating cell survival, through phosphorylation of IRS-1. Activated Akt blocks apoptotic signal by phosphorylating and inactivating Bad which otherwise would translocate to mitochondria, bind and neutralize its anti-apoptotic partners, such as, BCL-2 [22]. BCL-2, which is overexpressed in $50-70 \%$ of breast cancers contributing to the development of resistance to chemotherapy, radiation and hormone

*Corresponding author: Ezharul Hoque Chowdhury, Advanced Engineering Platform and Jeffrey Cheah School of Medicine and Health Sciences, Monash University Malaysia, Tel: 603-5514-4978; Fax: 603-5514-6323; E-mail: md.ezharul.hoque@monash.edu

Received August 22, 2014; Accepted October 22, 2014; Published October 30 , 2014

Citation: Kunnath AP, Kamaruzman NI, Chowdhury EH (2014) Nanoparticlefacilitated Intratumoral Delivery of Bcl-2/IGF-1R siRNAs and p53 Gene Synergistically Inhibits Tumor Growth in Immunocompetent Mice. J Nanomed Nanotechnol 6: 278. doi:10.4172/2157-7439.1000278

Copyright: (c) 2014 Kunnath AP, et al. This is an open-access article distributed under the terms of the Creative Commons Attribution License, which permits unrestricted use, distribution, and reproduction in any medium, provided the original author and source are credited. 
therapy-induced apoptosis [23-25], inhibits pro-apoptotic protein, BAX, thus preventing cytochrome $\mathrm{C}$ release from mitochondria and blocking apoptotic pathway [26,27]. In contrast, activation of p53, a tumor suppressor which is found mutated in $\sim 23 \%$ of breast cancer samples, leads to the activation of BAX [27]. Although p53 is maintained at very low level due to proteasomal degradation of p53 through MDM2, an E3 ubiquitin ligase, cellular stress-induced posttranslational modification of p53 and MDM2 stabilizes and activates p53 enabling it not only to activate BAX, but also to translocate to the nucleus and bind DNA in a sequence-specific manner and regulating the expression of hundreds of genes for cycle checkpoint activation, cellular senescence and apoptosis $[28,29]$. Thus, proliferation, survival and apoptosis of breast cancer cells are regulated by the concerted action of IGF-1R, BCL-2 and p53 signaling pathways.

Given that overexpression of IGF-1R and BCL-2 with frequent alteration of $\mathrm{p} 53$ leads to development, progression and chemoresistance of breast cancer, knockdown of the overexpressed gene(s), such as, IGF$1 \mathrm{R}$ and $\mathrm{Bcl}-2$ with precisely designed small interfering RNA (siRNA) and providing the wild-type p53 gene could be pivotal in effective treatment of the cancer. A number of existing non-viral vectors are available for intracellular delivery of siRNA and plasmid DNA to silence the target mRNA of a particular gene and to express a protein of interest, respectively, with limitations in proper condensation, cellular uptake and endosomal escape, leading to a decrease in overall performance of the delivered siRNA or DNA [30,31]. Recently, we developed $\mathrm{pH}$-responsive carbonate apatite nanoparticles to efficiently deliver siRNA as well as DNA across the cell membrane and facilitate them to release from the particles and endosomal vesicles to carry out knockdown of a specific mRNA transcript or expression of a desirable protein, respectively $[32,33]$. Moreover, we demonstrated nanoparticleassisted delivery of the siRNAs targeting cyclin B1, PLC-gamma-2/ calmodulin 1, HER2/ErbB2, ABCG2/ABCB1 and cROS1 mRNAs sensitizes cervical adenocarcinoma and breast cancer cells towards traditional anti-cancer drugs [34-38]. Here, we report that combined delivery of the siRNA against IGF-1R and Bcl-2 gene transcripts along with p53 gene using carbonate apatite nanoparticles synergistically induces death or growth inhibition of breast cancer cell lines as well as regression of the breast tumor induced in Balb/c mice. Moreover, intravenous delivery of nanoparticle-associated IGF-1R/Bcl-2 siRNAs and p53 gene apparently slow down the growth of the established tumor in presence of doxorubicin or paclitaxel compared with the individual free drug.

\section{Materials and Methods}

\section{Reagents}

Dulbecco's modified Eagle medium (DMEM) was purchased from BioWhittaker (Walkersville, USA). DMEM powder, foetal bovine serum (FBS) and trypsin-ethylenediaminetetraacetate (trypsin-EDTA) were obtained from Gibco BRL (California, USA). Calcium chloride dehydrate $\left(\mathrm{CaCl}_{2} .2 \mathrm{H}_{2} \mathrm{O}\right)$, sodium bicarbonate, dimethyl sulphoxide (DMSO) and thiazolyl blue tetrazolium bromide (MTT) were from Sigma-Aldrich (St Louis, MO, USA). The chemotherapy drugs, doxorubicin, paclitaxel and cis-diammineplatinum (II) dichloride) are from Sigma Aldrich (St.Louis, USA). Both doxorubicin and cisdiammineplatinum (II) dichloride were dissolved indistilled water and $2 \mathrm{mM}$ stock solutions were prepared whereas paclitaxel was dissolved in DMSO and $10 \mathrm{mM}$ stock solution was prepared.

\section{siRNA design and sequence}

The validated anti-IGF-1R and anti-Bcl-2 siRNAs were purchased from QIAGEN (California, US) with the target sequences of 5'-ATGGAGAATAATCCAGTCCTA-3' and 5'AACCGGGAGATAGTGATGAAG-3', respectively. siRNAs were supplied in lyophilised form and upon delivery, the siRNA (1 nmol) was reconstituted with RNase-free water to obtain a stock solution of $20 \mu \mathrm{M}$. The siRNA solution was then allocated in to multiple reaction tubes for storage as repeated thawing might affect the silencing efficiency of siRNAs. The siRNAs were stored at $20^{\circ} \mathrm{C}$ as recommended by QIAGEN.

\section{Isolation of p53}

E coli DH5a cells harboring p53 plasmid were grown in LB media overnight at $37^{\circ} \mathrm{C}$ (Kanamycin was added at a concentration of $50 \mu \mathrm{g} / \mathrm{ml}$ culture). Next day small colonies were picked and grown individually in $50 \mathrm{ml}$ of LB broth with kanamycin for 16 hour. The p53 plasmids were isolated and purified from the bacteria using 'Qiagen Plasmid Mega' kit. The extracted DNA was subjected to spectrophotometric quantification by taking absorbance at $260 \mathrm{~nm}$ while a ratio of absorbance at 260 and $280 \mathrm{~nm}$ at 1.8 or more was considered to be of high purity. Additionally, purified DNA was run on $0.8 \%$ agarose gel and the DNA bands were visualized under ultraviolet transilluminator.

\section{Cell culture and seeding}

MCF-7 and 4T1cells were grown in $25 \mathrm{~cm}^{2}$ culture flask in DMEM supplemented with $10 \%$ heat-inactivated FBS in a humidified atmosphere containing $5 \% \mathrm{CO}_{2}$ at $37^{\circ} \mathrm{C}$. Exponentially growing MCF-7 and $4 \mathrm{~T} 1$ cells were trypsinised and following addition of fresh medium, the cell suspension was centrifuged at $10,000 \mathrm{rpm}$ for $5 \mathrm{~min}$ and the supernatant was discarded. Fresh medium was added to resuspend the pellet and the cells were counted using haemocytometer. Appropriate dilutions were made using culture medium to produce a cell suspension with concentration $5.0 \times 10^{4}$ cells $/ \mathrm{ml}$. One $\mathrm{ml}$ of the prepared cell suspension was subsequently added into each of the wells in 24-well plate and allowed to attach for overnight at $37^{\circ} \mathrm{C}$ and $5 \% \mathrm{CO}_{2}$ before siRNA transfection.

\section{Formulation of carbonate apatite complexes of IGF-1R siRNA, Bcl-2 siRNA and/or p53 plasmid and transfection of MCF-7 and 4T1 cells}

On the day of transfection, $100 \mathrm{~mL}$ of DMEM was prepared using $1.35 \mathrm{~g}$ of DMEM powder and $0.37 \mathrm{~g}$ of sodium bicarbonate with the $\mathrm{pH}$ subsequently adjusted to 7.4 using $0.1 \mathrm{M}$ hydrochloric acid. The prepared DMEM solution was filtered using $0.2 \mu \mathrm{M}$ syringe filter in laminar flow hood, followed by transferring $1 \mathrm{ml}$ of the filtered medium into $1.5 \mathrm{ml}$ microcentrifuge tubes. $4 \mu \mathrm{l}$ of $1 \mathrm{M}$ calcium chloride was then added into the microcentrifuge tubes, followed by addition of siRNAs $(40 \mathrm{nM})$ and p53 plasmid DNA (100 ng) either individually or in combination and incubation at $37^{\circ} \mathrm{C}$ for $30 \mathrm{~min}$. After the incubation, $10 \%$ FBS was added into each microcentrifuge tube. Culture medium from the wells seeded one day before was aspirated and replaced with 1 $\mathrm{mL}$ of the prepared medium containing siRNA(s)-, p53- or siRNA(s)/ p53-loaded carbonate apatite nanoparticles in presence or absence of free drugs. Plates were then incubated at $37^{\circ} \mathrm{C}$ and $5 \% \mathrm{CO}_{2}$ for two consecutive days.

\section{Cell viability assessment with 3-(4,5-dimethylthiazol-2-yl)- 2,5-diphenyltetrazolium bromide (MTT) assay}

Two days after transfection with siRNA(s)-, p53- or siRNA(s)/p53loaded carbonate apatite nanoparticles, the fraction of viable MCF-7 and $4 \mathrm{~T} 1$ cells was determined using MTT assay. Briefly, $50 \mu \mathrm{L}$ of MTT 
Citation: Kunnath AP, Kamaruzman NI, Chowdhury EH (2014) Nanoparticle-facilitated Intratumoral Delivery of Bcl-2/IGF-1R siRNAs and p53 Gene Synergistically Inhibits Tumor Growth in Immunocompetent Mice. J Nanomed Nanotechnol 6: 278. doi:10.4172/2157-7439.1000278

Page 3 of 9

( $5 \mathrm{mg} / \mathrm{mL}$ in PBS) was added aseptically into each of the wells in siRNA transfected-plate, followed by incubation at $37^{\circ} \mathrm{C}$ and $5 \% \mathrm{CO}_{2}$ for $4 \mathrm{~h}$. After the incubation, medium containing MTT was aspirated and the purple formazan crystals at the bottom of each well were dissolved by mixing with $300 \mu \mathrm{L}$ of DMSO solution. Absorbance of the resulting formazan solution was then determined spectrophotometrically at wavelength $595 \mathrm{~nm}$ using microplate reader (DynexOpsys MR, US) with reference to $630 \mathrm{~nm}$. Each experiment was performed in triplicates and the data were plotted as mean \pm standard deviation (S.D.) of three independent experiments.

\section{Data analysis}

The cell viability in the treated wells was expressed as a percentage and was calculated using the absorbance values obtained from MTT assay by using the following formula:

$$
\% \text { Cell viability }=\frac{\text { Absorbance of treated sample }}{\text { Absorbance of control }} \times 100 \%
$$

\section{Tumour induction in Balb/c mice}

The IMU animal ethics committee approved all the procedures used in the project with the approval no. being IMU 220/2010. Fiveweeks-old female Balb/c mice were purchased from Institute for Medical Research (IMR) and were housed under standard conditions according to appropriate animal care guidelines. The animals were housed in plastic cages with 3 mice placed in each cage inside a well-ventilated room at $22 \pm 2^{\circ} \mathrm{C}$ with a 12 -hr L:D cycle. The mice groups were fed with regular ad libitum. All the animals had free access to standard diet and water. $1 \times 10^{5}$ cells murine breast cancer $4 \mathrm{~T} 1$ cells were injected subcutaneously into the mammary fat pad. When tumors reached around $75 \mathrm{~mm}^{3}$, the mice were randomly assigned to different groups for further study or treatments with six mice per group.
Intratumoral delivery of nanoparticle-associated IGF-1R siRNA, Bcl-2 siRNA, p53 plasmid or IGF-1R/Bcl-2 siRNA / p53 plasmid in Balb/c mice with 4T1 mammary carcinoma

In order to estimate gross body weight and subsequently, tumor volume regression, following induction of 4T1-induced mammary tumors, nanoparticle complexes of IGF-1R siRNA, Bcl-2 siRNA, p53 plasmid or IGF-1R/Bcl-2 siRNA /p53 plasmid were directly injected into the tumor. For a comparative study, medium, nanoparticles and free anti-cancer drugs were injected in both of the studies. Depending on the grouping, the mice were treated with $100 \mu \mathrm{l}$ of the particle suspension originally formulated in $1 \mathrm{ml}$ of DMEM with $7 \mathrm{mM}$ of $\mathrm{Ca}^{2+}$ in presence or absence of the complexes of IGF-1R siRNA ( $800 \mathrm{nM})$, Bcl-2 siRNA (800 nM), p53 plasmid (100 ng) or IGF-1R (800 nM)/ Bcl-2 siRNA ( $800 \mathrm{nM}) / \mathrm{p} 53$ plasmid (100 ng) and/or anticancer drugs $(100 \mathrm{nM})$, through intratumoral injection and the tumor volumes were estimated according to the modified ellipsoidal formula: $1 / 2$ (length $\times$ width $^{2}$ ).

\section{Statistical analysis}

Statistical analysis was done using the Mann-Whitney U test, a nonparametric test to compare the significant difference between treated and non-treated samples. Data is presented as mean \pm SD with $\mathrm{P}<0.05$ being considered as statistically significant.

\section{Results and Discussion}

Intracellular delivery of IGF-1R siRNA, Bcl-2 siRNA and p53 plasmid individually or in combinations into MCF-7 and $4 \mathrm{~T} 1$ breast cancer cells

Since expression of IGF-1R and Bcl-2 and 'loss of function' by

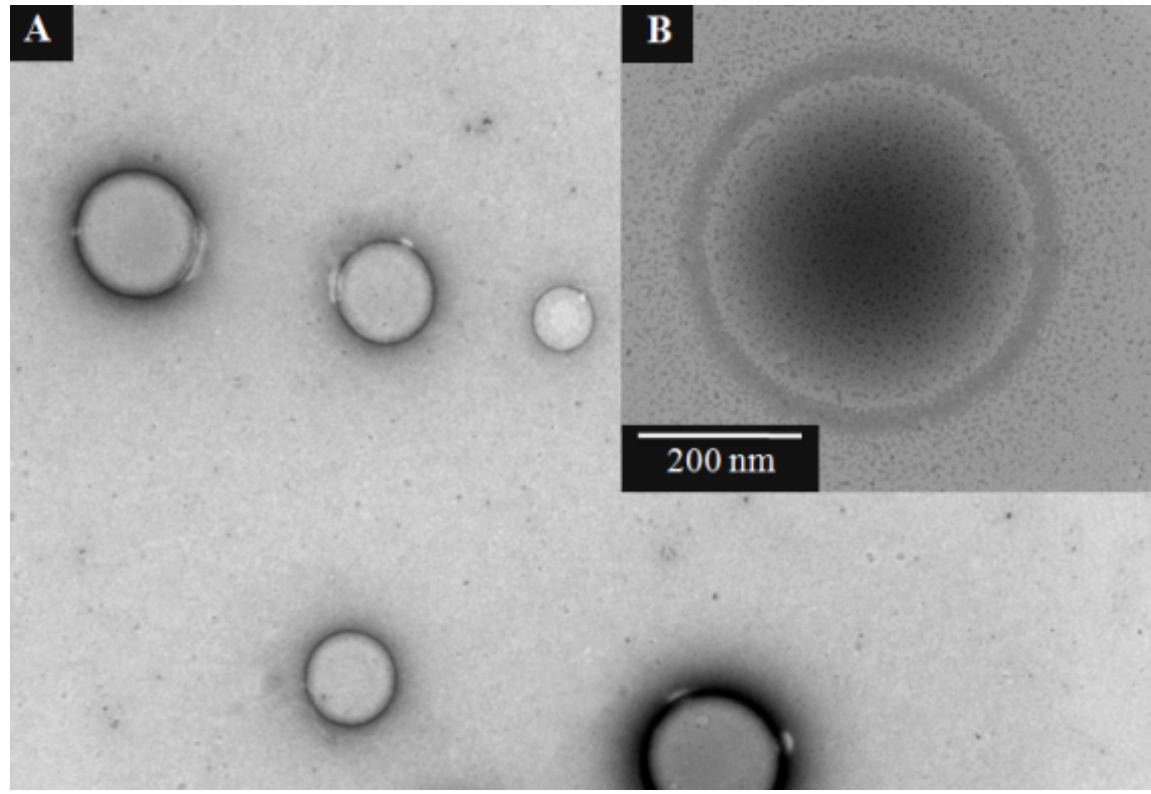

Figure 1: Cell viability study in vitro with MCF-7: untreated cells $(C)$, nanoparticle-treated cells (C+N), Bcl-2 siRNA-treated cells (C+N+BCL2), IGF-1R siRNAtreated cells (C+N+IGFR), IGF-1R siRNA- and p53-treated cells (C+N+IGFR+p53), IGF-1R siRNA- and Bcl-2 siRNA-treated cells (C+N+IGFR+BCL2), Bcl-2 siRNA- and p53-treated cells ( $\mathrm{C}+\mathrm{N}+\mathrm{BCL} 2+\mathrm{p} 53)$, IGF-1R/Bcl-2 siRNAs- and p53-treated cells (C+N+IGFR+BCL2+p53). IGF-1R siRNA-, Bcl-2 siRNA- and/or p53 plasmid-loaded carbonate apatite particles were generated by exogenous addition of $4 \mu \mathrm{l}$ of $1 \mathrm{M}$ calcium chloride, siRNA (40 nM) and/or plasmid (100 ng) to $1 \mathrm{~mL}$ bicarbonate-buffered DMEM (pH7.4), followed by incubation at $37^{\circ} \mathrm{C}$ for $30 \mathrm{~min}$ and supplementation with $10 \%$ FBS prior to incubation with MCF-7 cells for a consecutive period of $48 \mathrm{~h}$. MTT assay was subsequently performed with the absorbance being taken at wave length of 570 nm with reference to $630 \mathrm{~nm}$. Vertical bars represent standard error, ${ }^{*} \mathrm{P}<0.05$ vs control (untreated cells) or ${ }^{* *} \mathrm{P}<0.05$ vs control (nanoparticle-treated cells). 

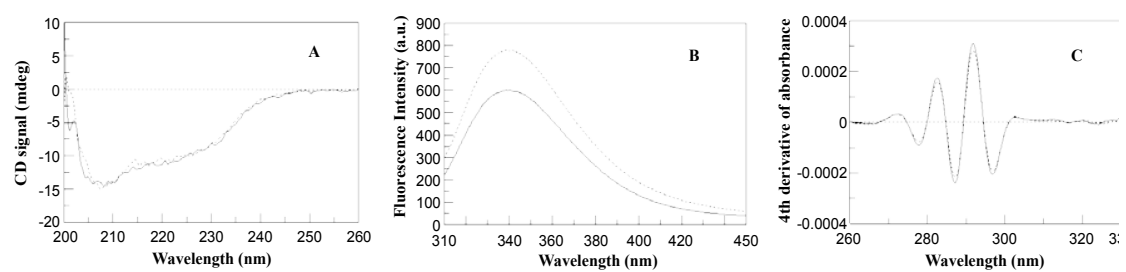

Figure 2: Cell viability study in vitro with 4T1: untreated cells (C), nanoparticle-treated cells (C+N), Bcl-2 siRNA-treated cells (C+N+BCL2), IGF-1R siRNAtreated cells (C+N+IGFR), IGF-1R siRNA- and p53-treated cells ( $+N+I G F R+p 53), I G F-1 R$ siRNA- and Bcl-2 siRNA-treated cells (C+N+IGFR+BCL2), Bcl-2 siRNA- and p53-treated cells (C+N+BCL2+p53), IGF-1R/Bcl-2 siRNAs- and p53-treated cells (C+N+IGFR+BCL2+p53). IGF-1R siRNA-, Bcl-2 siRNA- and/or p53 plasmid-loaded carbonate apatite particles were generated by exogenous addition of $4 \mu \mathrm{l}$ of $1 \mathrm{M}$ calcium chloride, siRNA (40 nM) and/or plasmid (100 ng) to 1 $\mathrm{mL}$ bicarbonate-buffered DMEM (pH7.4), followed by incubation at $37^{\circ} \mathrm{C}$ for $30 \mathrm{~min}$ and supplementation with $10 \%$ FBS prior to incubation with $4 \mathrm{~T} 1 \mathrm{cells}$ for a consecutive period of $48 \mathrm{~h}$. MTT assay was subsequently performed with the absorbance being taken at wave length of 570 nm with reference to 630 $\mathrm{nm}$. Vertical bars represent standard error, ${ }^{*} \mathrm{P}<0.05$ vs control (untreated cells) or ${ }^{* *} \mathrm{P}<0.05$ vs control (nanoparticle-treated cells).

mutated tumor suppressor genes, such as p53, and the cross-talks between them could contribute to the development of a variety of breast cancers, knockdown of IGF-1R and Bcl-2 transcripts and expression of wild-type p53 into breast cancer cells might block the cell proliferation and survival routes while stimulating apoptotic pathway. Carbonate apatite nanoparticles were used to complex with the siRNAs against IGF-1R and Bcl-2 (synthesized and validated by Qiagen) and p53 plasmid DNA, either individually or in combination, prior to the $48 \mathrm{~h}$ incubation with MCF-7 (human breast cancer cell line) and $4 \mathrm{~T} 1$ (murine breast cancer cell line). As shown in Figure 1, treatment of MCF-7 cells which express both IGF-1R [39,40] and Bcl-2 proteins [25] and possess wild-type p53 [41,42], with the nanoparticles carrying either IGF-1R siRNA, Bcl-2 siRNAs or p53 plasmid apparently enhanced killing of MCF-7 cells or inhibited the cell growth in comparison with the nanoparticles alone. However, the combined delivery of IGF-1R siRNA+p53 plasmid, IGF-1R siRNA+Bcl-2 siRNA or Bcl-2 siRNA+p53 plasmid did not further improve the efficacy of cell killing except IGF-1R siRNA+Bcl-2 siRNA+p53 plasmid $(\mathrm{p}<0.01)$, which could be due to the interactions among IGF-1R, Bcl-2 and p53 signaling pathways as discussed above, leading to a synergistic effect in reducing cell viability. A similar finding was observed in $4 \mathrm{~T} 1$ cells (Figure 2) which also possess IGF-1R [43,44] and bcl-2 [45], but are deficient of p53 [46,47], indicating that the seeming synergistic effect of IGF-1R siRNA+Bcl-2 siRNA+p53 plasmid $(\mathrm{p}<0.01)$ might be due to the concerted role of IGF-1R as well as Bcl-2 knockdown and overexpression of $\mathrm{p} 53$ gene. A statistically significant effect was also exerted by Bcl-2 siRNA $+\mathrm{p} 53$ plasmid $(\mathrm{p}<0.05)$ in comparison with the nanoparticle-treated cells. Although in $4 \mathrm{~T} 1$ cells (Figure 2 ) there was statistically no difference in cell viability between $\mathrm{p} 53+\mathrm{Bcl}-2$ and p53+Bcl-2+IGFR groups, in MCF-7 cells (Figure 1) p53+Bcl-2+IGFR group apparently showed stronger cytotoxic effects than $\mathrm{p} 53+\mathrm{Bcl}-2$ one compared to the control. Since breast cancer is heterogeneous in nature consisting of different types of cells, we thought that it would be better to investigate the effect of $\mathrm{p} 53+\mathrm{Bcl}-2+\mathrm{IGFR}$ rather than $\mathrm{p} 53+\mathrm{Bcl}-2$ on tumor regression in absence or presence of classical anti-cancer drugs. No cytotoxic effect was observed with 'All Stars Negative Control siRNA' having no target sequence within the cellular mRNA pool irrespective of the siRNA doses used (not shown here), indicating the role of siRNA specificity in gene knockdown and consequential effect on cellular fate. All the siRNAs used in this study were validated with RT-PCR by the manufacturer (Qiagen). It should be noted that we had extensively analyzed the morphology, size distribution and zeta potential of carbonate apatite nanoparticles by transmission electron microscope (TEM), scanning electron microscope (SEM), dynamic light scattering (DLS) and zeta sizer in our earlier publications. Moreover, we had reported on siRNA binding affinity towards the nanoparticles, cellular uptake and knockdown efficacy using reporter gene assays [32-38]. We have therefore not included those data in the current manuscript.

\section{Intratumoral delivery of IGF-1R siRNA, Bcl-2 siRNA and p53 plasmid individually or in combinations}

In order to further evaluate the potential synergistic effect in an immune-competent model of aggressive breast cancer of IGF-1R/ Bcl-2 knockdown and wild-type p53 expression in inducing death or inhibiting growth of tumor cells as observed in vitro in human and murine breast cancer cell lines irrespective of the presence or absence of normal p53, nanoparticle formulations of IGF-1R siRNA, Bcl-2 siRNA and wild-type $\mathrm{p} 53$ gene in various combinations were directly injected into the tumor of $4 \mathrm{~T} 1$ cells established in mammary fat pad of Balb/c mice. As shown in Figure 3, although there was virtually no change in the average body weights of the mice treated intratumorally (following induction of the tumors of measurable size using subcutaneously injected $4 \mathrm{~T} 1$ cells) with the combination of IGF-1R siRNA, Bcl-2 siRNA and wild-type $\mathrm{p} 53$ plasmid compared with the untreated control group, 
Citation: Kunnath AP, Kamaruzman NI, Chowdhury EH (2014) Nanoparticle-facilitated Intratumoral Delivery of Bcl-2/IGF-1R siRNAs and p53 Gene Synergistically Inhibits Tumor Growth in Immunocompetent Mice. J Nanomed Nanotechnol 6: 278. doi:10.4172/2157-7439.1000278
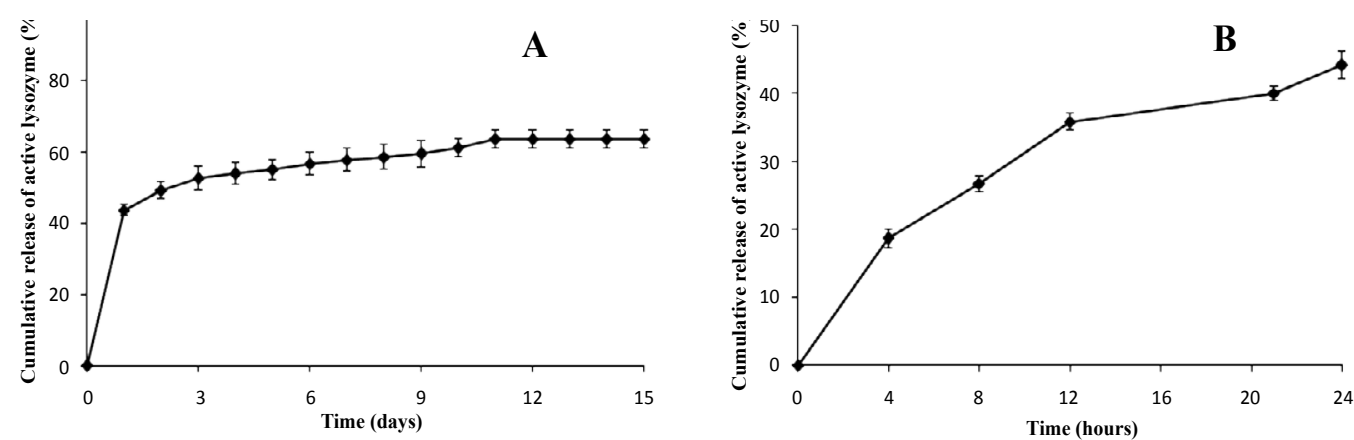

Figure 3: Effects on gross body weights of the mice group after intratumoral injection of nanoparticles alone, nanoparticles loaded with Bcl-2 siRNA, IGF-1R siRNA, p53 plasmid or IGF-1R/Bcl-2 siRNAs plus p53 plasmid, and cisplatin, doxorubicin or paclitaxel.
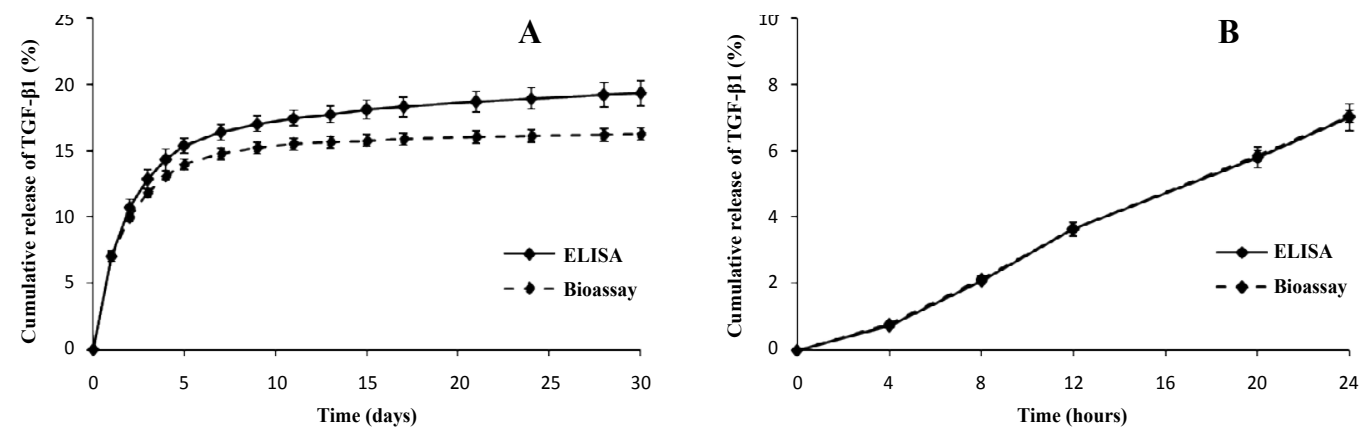

Figure 4: Effect on gross tumor volume regression following intratumoral injection of the nanoparticles loaded with Bcl-2 siRNA, IGF-1R siRNA, p53 plasmid or IGF-1R/Bcl-2 siRNAs plus p53 plasmid. The mice bearing 4T1-induced mammary tumor were treated with $100 \mu$ l of the particle suspension originally formulated in $1 \mathrm{ml}$ of DMEM with $7 \mathrm{mM}$ of $\mathrm{Ca}^{2+}$ in presence or absence of $800 \mathrm{~nm}$ of each of the siRNAs plus $100 \mathrm{ng}$ of p53, through intratumoral injection and the body weight was measured throughout the experiment from day 1 to day 29 . 
there was a noticeable and statistically significant reduction in tumor growth $(\mathrm{p}<0.05)$ over the period of observation in the particular group of mice receiving intratumoral injection of the particle formulation carrying IGF-1R/Bcl-2 siRNAs and p53 plasmid (Figure 4), suggesting an apparent synergistic effect of IGF-1R/Bcl-2 siRNAs plus $\mathrm{p} 53$ plasmid on tumor growth. The absence of total inhibition of tumor growth could be attributed to the injection frequency of the samples, which was once on day 22 following subcutaneous injection of cancer cells (4T1) in our current experimental set-up and thus the effects were very likely to subside in the later phase due to the nuclease-mediated cleavage of siRNA and DNA molecules.

Influences of IGF-1R and BCL-2 knockdown and wild-type p53 expression on traditional anti-cancer drug-induced tumor regression

Conventional chemotherapy which is based on anti-cancer drugs, such as cisplatin, doxorubicin or paclitaxel with known therapeutic efficacy in malignant breast cancer $[48,49]$ has its own shortcoming due to the toxic effects of the drugs on normal healthy cells and consequently the dosages of the drugs subsequently given to the patients are therapeutically insufficient leading to chemoresistance and tumor recurrence [50,51] with the vast majority of initially chemoresponsive tumours developing resistance to once effective chemotherapeutic agents. Moreover, a switch to other chemotherapy regimens is ineffective because of the tumour's cross-resistance to multiple chemotherapy drugs [50,51]. Blocking of the cell proliferation/ survival pathways by silencing their key regulatory molecules and/or activating the tumor suppressing pathway by over-expressing a wildtype tumor suppressor gene could either play an additive role or exert a synergistic effect through a potential 'cross-talk' with an anti-cancer drug, augmenting the overall therapeutic efficacy. In order to explore whether the intratumoral delivery of nanoparticle-embedded IGF-1R/ Bcl-2 siRNAs and wild-type p53 gene could synergize with the antitumor effects of the conventional drugs, cisplatin was injected directly into the tumors growing in the mammary fat pad of $\mathrm{Balb} / \mathrm{c}$ mice either in free form or together with the nanoparticle complex of IGF-1R/Bcl-2 siRNAs and p53 plasmid. As shown in Figure 5, although free cisplatin demonstrated higher cytotoxic response than the nanoparticle complex of IGF-1R/Bcl-2 siRNAs and p53 plasmid, however, cisplatin when treated along with the complex could not further enhance the effect, suggesting a possible additive effect on the same population of tumor cells subjected to growth arrest or apoptosis. On the contrary, as for doxorubicin (Figure 6) as well as paclitaxel (Figure 7), the nanoparticle complex of IGF-1R/Bcl-2 siRNAs and p53 plasmid apparently showed an inhibition on the growth of the tumors particularly at the later stage of the experimental period compared with the free individual drugs, suggesting a concerted effect of IGF-1 and Bcl-2 knockdown in presence of p53 expression on regression of tumor growth. This could be explained by the earlier findings that both IGF-1R and Bcl2 signaling cascades mediate the cytotoxic effects of doxorubicin and

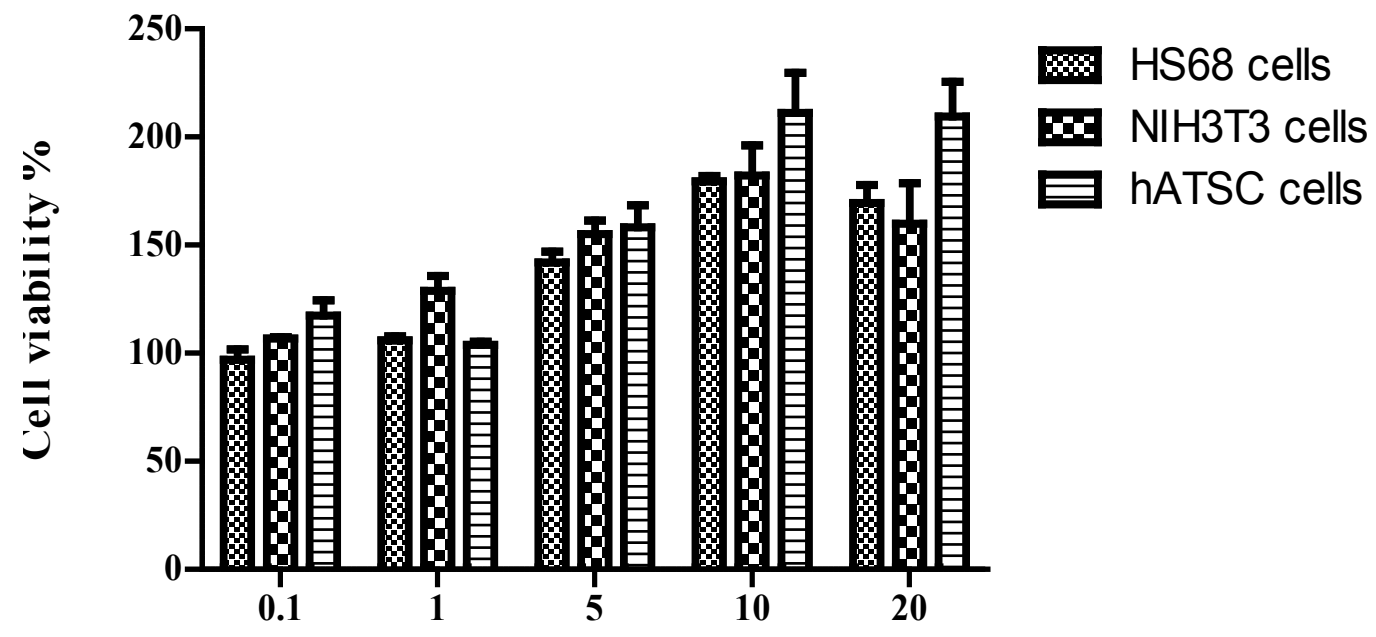

Unloaded nanoparticles concentration $(\mathrm{mg} / \mathrm{ml})$

Figure 5: Effect on gross tumor volume regression following intratumoral injection of the nanoparticles associated with IGF-1R/Bcl-2 siRNAs plus p53 plasmid in presence or absence of cisplatin. The mice bearing 4T1-induced mammary tumor were treated with $100 \mu$ l of the particle suspension originally formulated in $1 \mathrm{ml}$ of DMEM with $7 \mathrm{mM}$ of $\mathrm{Ca}^{2+}$ in presence or absence of $800 \mathrm{~nm}$ of each of the siRNAs plus $100 \mathrm{ng}$ of p53 and/or $100 \mathrm{nM}$ of cisplatin, through intratumoral injection and the tumor volumes were estimated according to the modified ellipsoidal formula: $1 / 2$ (length $\times$ width ${ }^{2}$ ). 
Citation: Kunnath AP, Kamaruzman NI, Chowdhury EH (2014) Nanoparticle-facilitated Intratumoral Delivery of Bcl-2/IGF-1R siRNAs and p53 Gene Synergistically Inhibits Tumor Growth in Immunocompetent Mice. J Nanomed Nanotechnol 6: 278. doi:10.4172/2157-7439.1000278

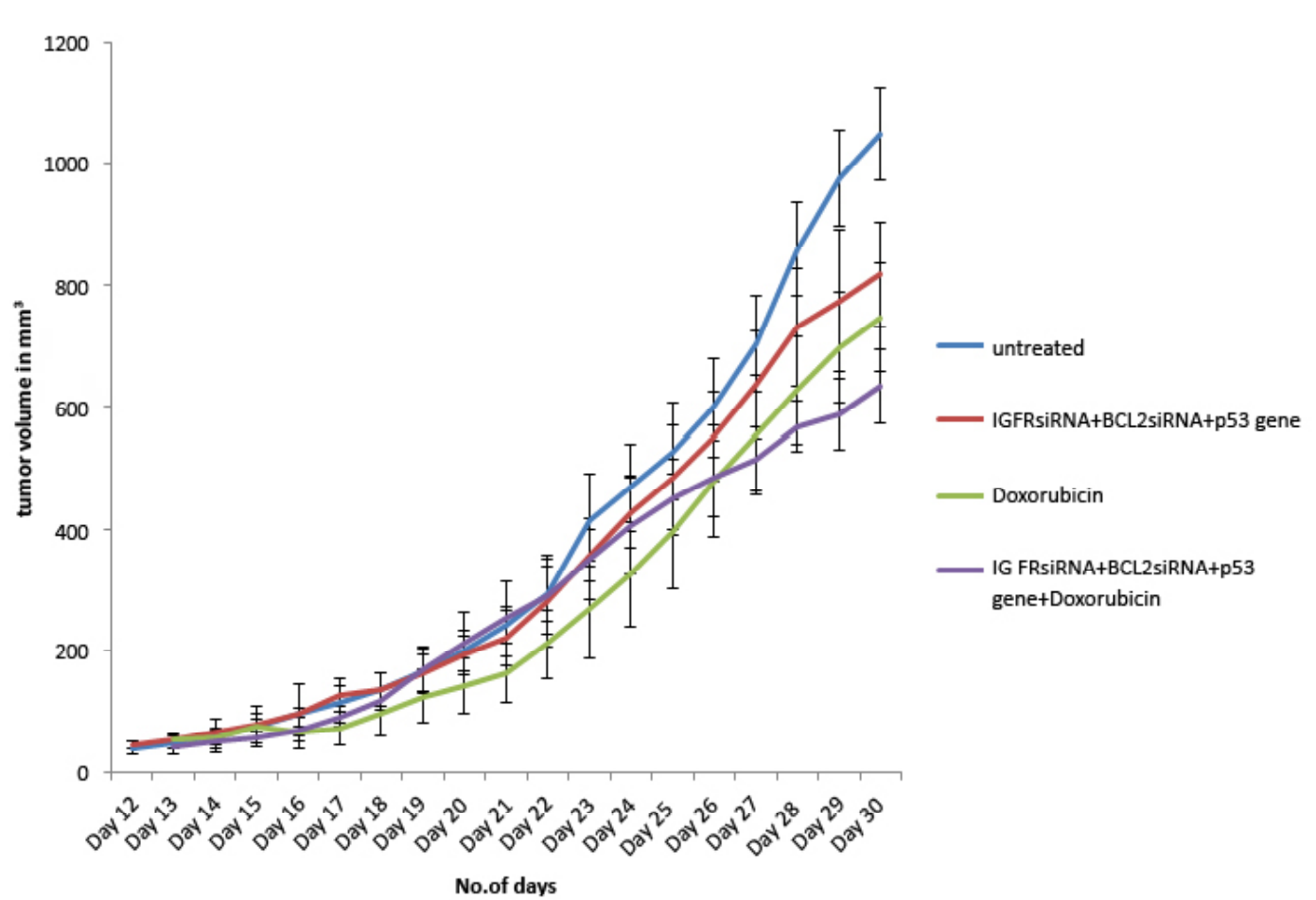

Figure 6: Effect on gross tumor volume regression following intratumoral injection of the nanoparticles associated with IGF-1R/Bcl-2 siRNAs plus p53 plasmid in presence or absence of doxorubicin. The mice bearing 4T1-induced mammary tumor were treated with $100 \mu$ l of the particle suspension originally formulated in $1 \mathrm{ml}$ of DMEM with $7 \mathrm{mM}$ of $\mathrm{Ca}^{2+}$ in presence or absence of $800 \mathrm{~nm}$ of each of the siRNAs plus $100 \mathrm{ng}$ of p53 and/or $100 \mathrm{nM}$ of doxorubicin, through intratumoral injection and the tumor volumes were estimated according to the modified ellipsoidal formula: $1 / 2$ (length $\times$ width ${ }^{2}$ ).

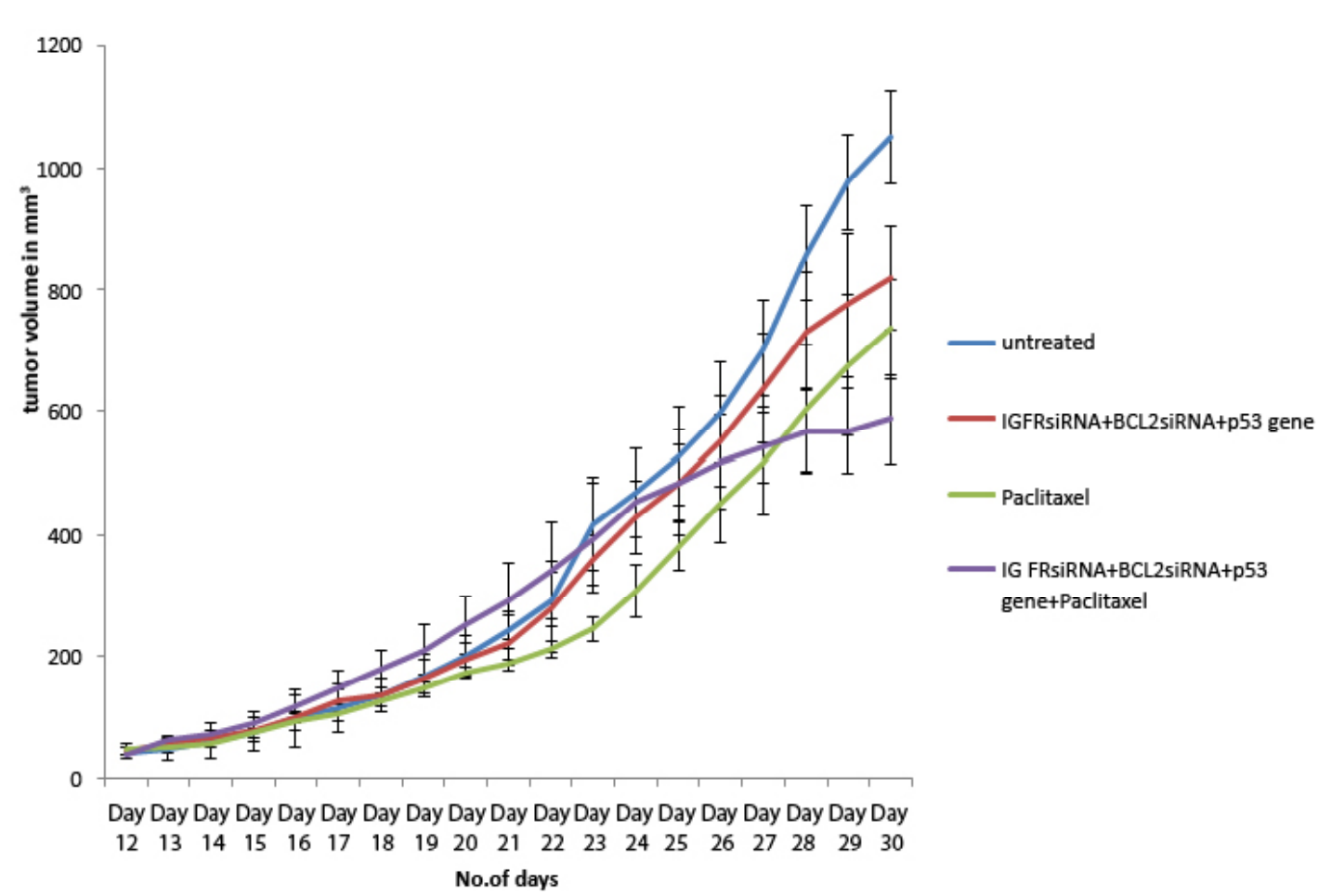

Figure 7: Effect on gross tumor volume regression following intratumoral injection of the nanoparticles associated with IGF-1R/Bcl-2 siRNAs plus p53 plasmid in presence or absence of paclitaxel. The mice bearing 4T1-induced mammary tumor were treated with $100 \mu \mathrm{l}$ of the particle suspension originally formulated in $1 \mathrm{ml}$ of DMEM with $7 \mathrm{mM}$ of $\mathrm{Ca}^{2+}$ in presence or absence of $800 \mathrm{~nm}$ of each of the siRNAs plus $100 \mathrm{ng}$ of p53 and/or $100 \mathrm{nM}$ of paclitaxel, through intratumoral injection and the tumor volumes were estimated according to the modified ellipsoidal formula: $1 / 2$ (length $\times$ width ${ }^{2}$ ). 
Citation: Kunnath AP, Kamaruzman NI, Chowdhury EH (2014) Nanoparticle-facilitated Intratumoral Delivery of Bcl-2/IGF-1R siRNAs and p53 Gene Synergistically Inhibits Tumor Growth in Immunocompetent Mice. J Nanomed Nanotechnol 6: 278. doi:10.4172/2157-7439.1000278

Page 8 of 9

paclitaxel [52-54]. Being a survival factor IGF-1 could interfere with the actions of the cytotoxic agents by increasing proliferation and inhibiting apoptosis of drug-treated cancer cells through activation of MAPK and PI-3 kinase pathways [52]. On the other hand, downregulation of $\mathrm{Bcl}-2$, one of most important mediators of survival and drug resistance in most human cancers, would enable induction of doxorubicin-triggered autophagy by relieving its suppressor activity on Beclin-1 (an autophagy-promoting protein), which is physically bound and blocked by Bcl-2 [53]. In addition, overexpression of Bcl2 generally protects cancer cells from paclitaxel-induced cell death by undergoing post-translation modification leading to mitochondrial apoptotic cell death $[54,55]$.

\section{Conclusion}

We have demonstrated that knockdown of IGF-1R and Bcl-2 genes as well as expression of normal p53 gene could be an attractive approach in synergistically suppressing the growth of an aggressive mouse tumor and additionally sensitizing the tumor towards doxorubicin and paclitaxel.

\section{Acknowledgement}

The work was supported by a research grant (02-02-10-SF0083) of the Ministry of the Science, Technology and Innovation, Malaysia.

\section{References}

1. Paik S, Shak S, Tang G, Kim C, Baker J, et al. (2004) A multigene assay to predict recurrence of tamoxifen-treated, node-negative breast cancer. $\mathrm{N}$ Engl J Med 351: 2817-2826.

2. van 't Veer LJ, Dai H, van de Vijver MJ, He YD, Hart AA, et al. (2002) Gene expression profiling predicts clinical outcome of breast cancer. Nature 415 : 530-536.

3. Slamon DJ, Clark GM, Wong SG, Levin WJ, Ullrich A, et al. (1987) Human breast cancer: correlation of relapse and survival with amplification of the HER2/neu oncogene. Science 235: 177-182.

4. Chin K, DeVries S, Fridlyand J, Spellman PT, Roydasgupta R, et al. (2006) Genomic and transcriptional aberrations linked to breast cancer pathophysiologies. Cancer Cell 10: 529-541.

5. Perou CM (2011) Molecular stratification of triple-negative breast cancers Oncologist 16 Suppl 1: 61-70

6. Fauvel B, Yasri A (2014) Antibodies directed against receptor tyrosine kinases: current and future strategies to fight cancer. MAbs 6: 838-851.

7. Arteaga CL, Engelman JA (2014) ERBB receptors: from oncogene discovery to basic science to mechanism-based cancer therapeutics. Cancer Cell 25 : 282-303.

8. Li SG, Li L (2013) Targeted therapy in HER2-positive breast cancer. Biomed Rep 1: 499-505.

9. Gacche RN, Meshram RJ (2013) Targeting tumor micro-environment for design and development of novel anti-angiogenic agents arresting tumor growth. Prog Biophys Mol Biol 113: 333-354.

10. Hassan M, Watari H, AbuAlmaaty A, Ohba Y, Sakuragi N (2014) Apoptosis and molecular targeting therapy in cancer. Biomed Res Int 2014: 150845.

11. Plati J, Bucur O, Khosravi-Far R (2011) Apoptotic cell signaling in cancer progression and therapy. Integr Biol (Camb) 3: 279-296.

12. Pollak M (2008) Insulin and insulin-like growth factor signalling in neoplasia Nat Rev Cancer 8: 915-928.

13. Sachdev D, Yee D (2007) Disrupting insulin-like growth factor signaling as a potential cancer therapy. Mol Cancer Ther 6: 1-12.

14. Resnicoff M, Abraham D, Yutanawiboonchai W, Rotman HL, Kajstura J, et al. (1995) The insulin-like growth factor I receptor protects tumor cells from apoptosis in vivo. Cancer Res 55: 2463-2469.

15. Sell C, Dumenil G, Deveaud C, Miura M, Coppola D, et al. (1994) Effect of a null mutation of the insulin-like growth factor I receptor gene on growth and transformation of mouse embryo fibroblasts. Mol Cell Biol 14: 3604-3612.
16. Sell C, Rubini M, Rubin R, Liu JP, Efstratiadis A, et al. (1993) Simian virus 40 large tumor antigen is unable to transform mouse embryonic fibroblasts lacking type 1 insulin-like growth factor receptor. Proc Natl Acad Sci U S A 90: 1121711221.

17. Dunn SE, Ehrlich M, Sharp NJ, Reiss K, Solomon G, et al. (1998) A dominant negative mutant of the insulin-like growth factor-I receptor inhibits the adhesion, invasion, and metastasis of breast cancer. Cancer Res 58: 3353-3361.

18. Sachdev D, Hartell JS, Lee AV, Zhang X, Yee D (2004) A dominant negative type I insulin-like growth factor receptor inhibits metastasis of human cancer cells. J Biol Chem 279: 5017-5024.

19. Zhu C, Qi X, Chen Y, Sun B, Dai Y, et al. (2011) PI3K/Akt and MAPK/ERK1/2 signaling pathways are involved in IGF-1-induced VEGF-C upregulation in breast cancer. J Cancer Res Clin Oncol 137: 1587-1594.

20. Klammt J, Pfäffle R, Werner H, Kiess W (2008) IGF signaling defects as causes of growth failure and IUGR. Trends Endocrinol Metab 19: 197-205.

21. Kruis T, Klammt J, Galli-Tsinopoulou A, Wallborn T, Schlicke M, et al. (2010) Heterozygous mutation within a kinase-conserved motif of the insulin-like growth factor I receptor causes intrauterine and postnatal growth retardation. J Clin Endocrinol Metab 95: 1137-1142.

22. Danial NN (2008) BAD: undertaker by night, candyman by day. Oncogene 27 Suppl 1: S53-70.

23. Reed JC, Cuddy M, Slabiak T, Croce CM, Nowell PC (1988) Oncogenic potential of bcl-2 demonstrated by gene transfer. Nature 336: 259-261.

24. Kitada S, Takayama S, De Riel K, Tanaka S, Reed JC (1994) Reversal of chemoresistance of lymphoma cells by antisense-mediated reduction of bcl-2 gene expression. Antisense Res Dev 4: 71-79.

25. Akar U, Chaves-Reyez A, Barria M, Tari A, Sanguino A, et al. (2008) Silencing of $\mathrm{Bcl}-2$ expression by small interfering RNA induces autophagic cell death in MCF-7 breast cancer cells. Autophagy 4: 669-679.

26. Juin P, Geneste O, Gautier F, Depil S, Campone M (2013) Decoding and unlocking the BCL-2 dependency of cancer cells. Nat Rev Cancer 13: 455-465.

27. Grimm D, Wehland M, Pietsch J, Infanger M, Bauer J (2011) Drugs interfering with apoptosis in breast cancer. Curr Pharm Des 17: 272-283.

28. Levine AJ, Oren M (2009) The first 30 years of p53: growing ever more complex. Nat Rev Cancer 9: 749-758.

29. Menendez D, Inga A, Resnick MA (2009) The expanding universe of p53 targets. Nat Rev Cancer 9: 724-737.

30. Chowdhury EH (2011) Strategies for tumor-directed delivery of siRNA. Expert Opin Drug Deliv 8: 389-401.

31. Chowdhury EH (2009) Nuclear targeting of viral and non-viral DNA. Expert Opin Drug Deliv 6: 697-703.

32. Hossain S, Stanislaus A, Chua MJ, Tada S, Tagawa Y, et al. (2010) Carbonate apatite-facilitated intracellularly delivered siRNA for efficient knockdown of functional genes. J Control Release 147: 101-108.

33. Hossain S, Tada S, Akaike T, Chowdhury EH (2010) Influences of electrolytes and glucose on formulation of carbonate apatite nanocrystals for efficient gene delivery to mammalian cells. Anal Biochem 397: 156-161.

34. Stanislaus A, Hossain S, Chua MJ, Kunnath AP, Wen QC, et al. (2011) Fabrication and intracellular delivery of siRNA/carbonate apatite nanocomposites for effective knockdown of cyclin B1 gene. Drugs and Ther Studies 1: e8

35. Stanislaus A, Bakhtiar A, Salleh D, Tiash S, Fatemian T, et al. (2012) Knockdown of PLC-gamma-2 and calmodulin 1 genes sensitizes human cervical adenocarcinoma cells to doxorubicin and paclitaxel. Cancer Cell Int 12: 30 .

36. Kunnath AP, Tiash S, Fatemian T, Morshed M, Shar SM, et al. (2014) Intracellular delivery of ERBB2 siRNA and p53 gene synergistically inhibits the growth of established tumor in an immunocompetent mouse. J Cancer Sci Ther 6: 099-104

37. Li YT, Chua MJ, Kunnath AP, Chowdhury EH (2012) Reversing multidrug resistance in breast cancer cells by silencing $A B C$ transporter genes with nanoparticle-facilitated delivery of target siRNAs. Int J Nanomedicine 7: 24732481. 
Citation: Kunnath AP, Kamaruzman NI, Chowdhury EH (2014) Nanoparticle-facilitated Intratumoral Delivery of Bcl-2/IGF-1R siRNAs and p53 Gene Synergistically Inhibits Tumor Growth in Immunocompetent Mice. J Nanomed Nanotechnol 6: 278. doi:10.4172/2157-7439.1000278

Page 9 of 9

38. Chua MJ, Tiash S, Fatemian T, Noordin MI, Keng CS, Chowdhury EH (2013) Carbonate apatite-facilitated intracellular delivery of c-ROS1 siRNA sensitizes MCF-7 breast cancer cells to cisplatin and paclitaxel. OA Cancer 1: 7.

39. Arteaga CL (1992) Interference of the IGF system as a strategy to inhibit breast cancer growth. Breast Cancer Res Treat 22: 101-106.

40. Surmacz E, Guvakova MA, Nolan MK, Nicosia RF, Sciacca L (1998) Type I insulin-like growth factor receptor function in breast cancer. Breast Cancer Res Treat 47: 255-267.

41. Wosikowski K, Regis JT, Robey RW, Alvarez M, Buters JT, et al. (1995) Normal p53 status and function despite the development of drug resistance in human breast cancer cells. Cell Growth Differ 6: 1395-1403.

42. Ogretmen B, Safa AR (1997) Expression of the mutated p53 tumor suppressor protein and its molecular and biochemical characterization in multidrug resistant MCF-7/Adr human breast cancer cells. Oncogene 14: 499-506.

43. Ryan AJ, Napoletano S, Fitzpatrick PA, Currid CA, O'Sullivan NC, et al. (2009) Expression of a protease-resistant insulin-like growth factor-binding protein-4 inhibits tumour growth in a murine model of breast cancer. $\mathrm{Br} \mathrm{J}$ Cancer 101: 278-286.

44. De Lorenzo MS, Baljinnyam E, Vatner DE, Abarzúa P, Vatner SF, et al. (2011) Caloric restriction reduces growth of mammary tumors and metastases. Carcinogenesis 32: 1381-1387.

45. Barr MP, Bouchier-Hayes DJ, Harmey JJ (2008) Vascular endothelial growth factor is an autocrine survival factor for breast tumour cells under hypoxia. Int $\mathrm{J}$ Oncol 32: 41-48.

46. Wang H, Mohammad RM, Werdell J, Shekhar PV (1998) p53 and protein kinase $\mathrm{C}$ independent induction of growth arrest and apoptosis by bryostatin 1 in a highly metastatic mammary epithelial cell line: In vitro versus in vivo activity. Int J Mol Med 1: 915-923.
47. Sang H, Pisarev VM, Chavez J, Robinson S, Guo Y, et al. (2005) Murine mammary adenocarcinoma cells transfected with p53 and/or Flt3L induce antitumor immune responses. Cancer Gene Ther 12: 427-437.

48. Hortobagyi GN (1995) Management of breast cancer: status and future trends. Semin Oncol 22: 101-107.

49. Cobleigh MA (2011) Other options in the treatment of advanced breast cancer Semin Oncol 38 Suppl 2: S11-16.

50. Modok S, Mellor HR, Callaghan R (2006) Modulation of multidrug resistance efflux pump activity to overcome chemoresistance in cancer. Curr Opin Pharmacol 6: 350-354.

51. Ambudkar SV, Dey S, Hrycyna CA, Ramachandra M, Pastan I, et al. (1999) Biochemical, cellular, and pharmacological aspects of the multidrug transporter Annu Rev Pharmacol Toxicol 39: 361-398.

52. Gooch JL, Van Den Berg CL, Yee D (1999) Insulin-like growth factor (IGF)-I rescues breast cancer cells from chemotherapy-induced cell death--proliferative and anti-apoptotic effects. Breast Cancer Res Treat 56: 1-10.

53. Tekedereli I, Alpay SN, Akar U, Yuca E, Ayugo-Rodriguez C, et al. (2013) Therapeutic Silencing of $\mathrm{Bcl}-2$ by Systemically Administered siRNA Nanotherapeutics Inhibits Tumor Growth by Autophagy and Apoptosis and Enhances the Efficacy of Chemotherapy in Orthotopic Xenograft Models of ER (-) and ER (+) Breast Cancer. Mol Ther Nucleic Acids 2: e121.

54. Bah N, Maillet L, Ryan J, Dubreil S, Gautier F, et al. (2014) Bcl-xL controls a switch between cell death modes during mitotic arrest. Cell Death Dis 5: e1291.

55. Kutuk O, Letai $A$ (2008) Alteration of the mitochondrial apoptotic pathway is key to acquired paclitaxel resistance and can be reversed by ABT-737. Cancer Res 68: 7985-7994.
This article was originally published in a special issue, Translational Nanoscience handled by Editor(s). Dr. Fatih M Uckun, University Southern California, USA 